Original article

\title{
FINGER REPLANTATION: GOOD AND BAD RESULTS
}

\author{
Wael Salama ${ }^{1}$, Yasser Soror ${ }^{1}$, Mohamed $\mathrm{Ali}^{1}$, Panayotis Soucacos ${ }^{1}$, Hassan Noaman ${ }^{1\left(^{*}\right)}$ \\ ${ }^{I}$ Orthopedic Surgery dept., Faculty of Medicine, Sohag Univ., Sohag, Egypt \\ ${ }^{2}$ Orthopedic research \& Education Center “Attikon" University Hospital, Athens, Greece \\ "E-mail: hassan_h@mailcity.com
}

\section{Received 17/1/2020}

Accepted 23/4/2020

\begin{abstract}
There are different causes for finger amputation. Causes are starting from clean cut amputation up to avulsion. There are many factors affecting the results of finger replantation, as cause of injury, age of the patient, level of amputation, time passed after injury, methods for preservation of the amputated part, trained surgeons, and surgical equipments. Other factors affect the results of finger replantation are number of digital amputation, surgeon comfortability, and patient cooperation. This study included 38 patients presented by amputation of 57 fingers. The average age was 23 years old. The main cause was machine injury. The dominant hand was the right hand. The dominant finger was the thumb. The level of injury was proximal to the proximal interphalangeal joint in most of cases. The average time passed between injury and replantation was 2 hours. The average time of surgery for one digit replantation was 4 hours. The principles of treatment was exploration of the neurovascular and tendons in the amputated digit initially then that of the stump. The order of treatment was bone fixation by 2 kirschner wire, digital artery, digital vein, flexor tendon, digital nerve, extensor tendon. Skin closure should be loose. The average follow up was 58 months. All fingers have been survived except five. The average time for bone union was 8 weeks. According to Chen's criteria, the overall results were classified as grade I (excellent) in 20 cases, grade II (good) in 16 cases and grade III (fair) in 2 cases. The tendon function was excellent in 20 fingers, good in 26 fingers fair in 3 fingers, poor in 2 fingers and failure in 6 fingers. The 2 point discrimination was $6 \mathrm{~mm}$ in 9 fingers, 7-10 mm in 29 fingers, and 12-15 $\mathrm{mm}$ in 13 fingers. The mean grip and pinch strengths were $80 \%$ and $85 \%$ respectively compared to contralateral hand. All of patient had returned to their normal daily activities. Finally, finger replantation is not an easy job and it is considered as challenging procedure even for the specialist. I think that many factors affecting the results of finger replantation have not been discovered yet.
\end{abstract}

Keywords: Digital amputation, Microvascular anastomosis, Replantation, Discrimination.

\section{Introduction}

There are many factors affecting the results of finger replantation [1-3]. Many authors [1-4] described these factors but the absence of ideal and standards measurements for comparison was seemed to be the main problem. The results of finger replantation were variable and the recorded successful rate was ranged between 70 -
$90 \%$ [1-4]. The common factors affecting the results were the age of the patient, the level of injury, the causative agent, the number of amputated finger in the same patient, the associated injuries, and time elapsed between injury and replantation, methods for preservation, surgical equipments, and surgeon experience. The aim of 
this study is to conclude that there are still factors affecting the functional outcome of finger replantation which did not described

\section{Patients and Methods}

This study included 38 patients presented by amputation of 57 fingers. This study had been done in academic level 1 trauma center, from January 2012 to January 2018. The average age was 23 years old. The majority was male affection (30 out of 38). Right hand was involved in 26 patients. The cause was machine injury in 14 pati-ents, clean cut amputation in 9 patients, fire arm injury in 5 patients, electrical saw in 4 patients, and motor car accident in 6 patients. Avulsion amputation, tip finger amputation, polytraumatized patients, and associated chronic medical diseases were excluded from this study. The injured finger was the thumb 19, index 13, middle 12 , ring 8 , and little 5 . The level of injury was proximal to the proximal interphalangeal joint in most of cases. The average time passed between injury andreplantation was 2 hours. The average time of surgery for one digit replantation was 4 hours. The average hospital staying was 7 days postoperatively, tab. (1). Every patient was assessed clinically and radiologically to exclude further injuries, to assess the general condition, to discover or treat other medical diseases. All patients obtained general anesthesia. The patient position was supine. The involved upper limb was sterilized and draped up to the tourniquet. The affected hand was put on side arm table with tourniquet. Exploration of the digital artery, digital nerve, subcutaneous vein, flexor tendons and extensor tendons in the amputated digit was done respectively. Then the same work was done in the proximal stump. Bone fixation was the first step. Two Kirschner wires were used to fix the bone in most cases. This was followed by digital artery repair, fig. (1). Sometimes the digital artery was too short or thrombosed or even macerated leaved gap. This was managed by doing anastomosis of the in the literature as surgeon comfortability and patient cooperation.

contralateral digital artery, reverse vein graft, transportation of the digital artery from the adjacent intact finger, or bone shortening. Digital vein anastomosis or graft was the difficult step in most of cases. This was facilitated by doing repair of the digital artery first then deflate the tourniquet and then the vein will engorge and appear obviously. Tendon repair was also important and it was taken cautiously to improve the functional outcome of digital replantation. Sometimes the proximal stump of the tendon was retracted and it was difficult to get it from the wound. Surgical wound over the transverse carpal ligament was the solution to get it and passed it through the lumbrical canal closely. Skin closure was done meticulously to avoid tightness of the wound and it may lead to ischemia of the finger. Below elbow slab was done for 4 weeks. Monitoring of finger was performed every hour in the first day, every 2 hours in the second day and every 6 hours for 5 days. The patient was discharged from the hospital one week postoperatively. Below elbow slab was removed after 4 weeks. Kirschner wires were removed after 6 weeks. Home physiotherapy was done for 2 weeks after kirschner wires removal, followed by physiotherapy. We used tendon function scale to assess both joint range of motion and tendon gliding. It is considered as excellent when the tip of the involved finger reached at or distal to the proximal palmer crease by one $\mathrm{cm}$, good when the tip of the involved finger is far from the proximal palmar crease by more than 1 $\mathrm{cm}$, poor when there was inappropriate finger movement and bad if there was no movement of the involved finger. The sensation was assessed clinically using the 2 point discrimination, excellent when it was less than $6 \mathrm{~mm}$, good $6-10 \mathrm{~mm}$, fair more than $10 \mathrm{~mm}$, and poor if there was trophic change. 
Table (1) Patient's data.

\begin{tabular}{|c|c|c|c|c|c|c|c|}
\hline Patient & Age & Sex & $\begin{array}{c}\text { Affected } \\
\text { hand }\end{array}$ & $\begin{array}{c}\text { Amputated } \\
\text { digit }\end{array}$ & Cause & $\begin{array}{c}\text { Time elapsed } \\
\text { before surgery } \\
\text { (h.) }\end{array}$ & $\begin{array}{c}\text { Operativ } \\
\text { e Time } \\
\text { (h.) }\end{array}$ \\
\hline 1 & 22 & $\mathrm{M}$ & $\mathrm{R}$ & Thumb & Knife & 3 & 4 \\
\hline 2 & 12 & $\mathrm{M}$ & $\mathrm{R}$ & little & Motor car & 2 & 4 \\
\hline 3 & 19 & M & $\mathrm{L}$ & $\begin{array}{l}\text { Index, } \\
\text { Middle }\end{array}$ & Firearm & 1 & 6 \\
\hline 4 & 18 & $\mathrm{M}$ & $\mathrm{R}$ & Thumb & Glass & 2 & 4 \\
\hline 5 & 26 & M & $\mathrm{L}$ & $\begin{array}{c}\text { Little, ring, } \\
\text { middle }\end{array}$ & Saw injury & 3 & 7 \\
\hline 6 & 32 & $\mathrm{M}$ & $\mathrm{R}$ & Thumb & Motor car & 4 & 5 \\
\hline 7 & 24 & $\mathrm{~F}$ & $\mathrm{~L}$ & Thumb & Knife & 2 & 4 \\
\hline 8 & 8 & M & $\mathrm{R}$ & $\begin{array}{l}\text { Thumb, index } \\
\text { and middle }\end{array}$ & Saw injury & 1 & 6 \\
\hline 9 & 35 & $\mathrm{M}$ & $\mathrm{R}$ & Ring & Glass & 1 & 4 \\
\hline 10 & 37 & $\mathrm{M}$ & $\mathrm{R}$ & Middle & Machine & 3 & 5 \\
\hline 11 & 7 & $\mathrm{M}$ & $\mathrm{R}$ & Thumb & Machine & 2 & 6 \\
\hline 12 & 41 & F & $\mathrm{L}$ & Index & $\begin{array}{l}\text { Glass } \\
\text { injury }\end{array}$ & 2 & 4 \\
\hline 13 & 6 & $\mathrm{M}$ & $\mathrm{L}$ & Index & Machine & 1 & 4 \\
\hline 14 & 15 & $\mathrm{M}$ & $\mathrm{R}$ & Thumb & Machine & 2 & 5 \\
\hline 15 & 17 & $\mathrm{M}$ & $\mathrm{R}$ & Thumb & Motor car & 4 & 5 \\
\hline 16 & 36 & $\mathrm{~F}$ & $\mathrm{R}$ & Ring & Glass injury & 5 & 4 \\
\hline 17 & 42 & M & $\mathrm{R}$ & $\begin{array}{c}\text { Thumb, index, } \\
\text { middle, ring }\end{array}$ & Motor car & 3 & 8 \\
\hline 18 & 23 & $\mathrm{~F}$ & $\mathrm{R}$ & Little & $\begin{array}{l}\text { Meat } \\
\text { grinding } \\
\text { machine }\end{array}$ & 6 & 3 \\
\hline 19 & 21 & $\mathrm{M}$ & $\mathrm{R}$ & Index & Glass & 4 & 4 \\
\hline 20 & 22 & $\mathrm{M}$ & $\mathrm{L}$ & Index & Firearm & 2 & 4 \\
\hline 21 & 11 & $\mathrm{M}$ & $\mathrm{R}$ & Middle & Firearm & 3 & 4 \\
\hline 22 & 19 & $\mathrm{~F}$ & $\mathrm{R}$ & $\begin{array}{l}\text { Thumb, index } \\
\text { middle ring, } \\
\text { little }\end{array}$ & $\begin{array}{c}\text { Grinding } \\
\text { corn } \\
\text { machine }\end{array}$ & 7 & 7 \\
\hline 23 & 36 & M & $\mathrm{R}$ & $\begin{array}{l}\text { Middle, ring, } \\
\text { little }\end{array}$ & Saw injury & 3 & 7 \\
\hline 24 & 38 & $\mathrm{M}$ & $\mathrm{R}$ & Thumb & Firearm & 2 & 4 \\
\hline 25 & 24 & M & $\mathrm{L}$ & $\begin{array}{c}\text { Thumb, } \\
\text { index, middle }\end{array}$ & $\begin{array}{l}\text { Motor car } \\
\text { accident }\end{array}$ & 4 & 7 \\
\hline 26 & 39 & $\mathrm{M}$ & $\mathrm{R}$ & Middle & Knife & 1 & 3 \\
\hline 27 & 30 & M & $\mathrm{R}$ & Thumb, index & $\begin{array}{l}\text { Grinding } \\
\text { corn } \\
\text { machine }\end{array}$ & 2 & 5 \\
\hline 28 & 25 & $\mathrm{M}$ & $\mathrm{L}$ & Thumb & Machine & 3 & 4 \\
\hline 29 & 27 & $\mathrm{~F}$ & $\mathrm{~L}$ & Thumb & $\begin{array}{c}\text { Meat } \\
\text { grinding } \\
\text { machine }\end{array}$ & 5 & 5 \\
\hline 30 & 36 & $\mathrm{M}$ & $\mathrm{R}$ & Middle, ring & Motor car & 4 & 6 \\
\hline 31 & 35 & $\mathrm{M}$ & $\mathrm{L}$ & Index & Firearm & 2 & 4 \\
\hline 32 & 24 & $\mathrm{M}$ & $\mathrm{R}$ & Thumb & Saw injury & 1 & 3 \\
\hline 33 & 12 & M & $\mathrm{R}$ & Index & $\begin{array}{l}\text { Biscuit } \\
\text { paste } \\
\text { machine }\end{array}$ & 4 & 4 \\
\hline
\end{tabular}




\begin{tabular}{|l|c|c|c|c|c|c|c|}
\hline $\mathbf{3 4}$ & 21 & $\mathrm{~F}$ & $\mathrm{R}$ & Thumb & Knife & 3 & 4 \\
\hline $\mathbf{3 5}$ & 25 & $\mathrm{M}$ & $\mathrm{L}$ & Ring & Machine & 2 & 4 \\
\hline $\mathbf{3 6}$ & 20 & $\mathrm{M}$ & $\mathrm{R}$ & Index, middle & $\begin{array}{c}\text { Grinding } \\
\text { meat } \\
\text { machine }\end{array}$ & 5 & 5 \\
\hline $\mathbf{3 7}$ & 35 & $\mathrm{~F}$ & $\mathrm{~L}$ & Thumb & $\begin{array}{c}\text { Kitchen } \\
\text { machine }\end{array}$ & 3 & 4 \\
\hline $\mathbf{3 8}$ & 38 & $\mathrm{M}$ & $\mathrm{R}$ & Thumb & Machine & 6 & 5 \\
\hline
\end{tabular}
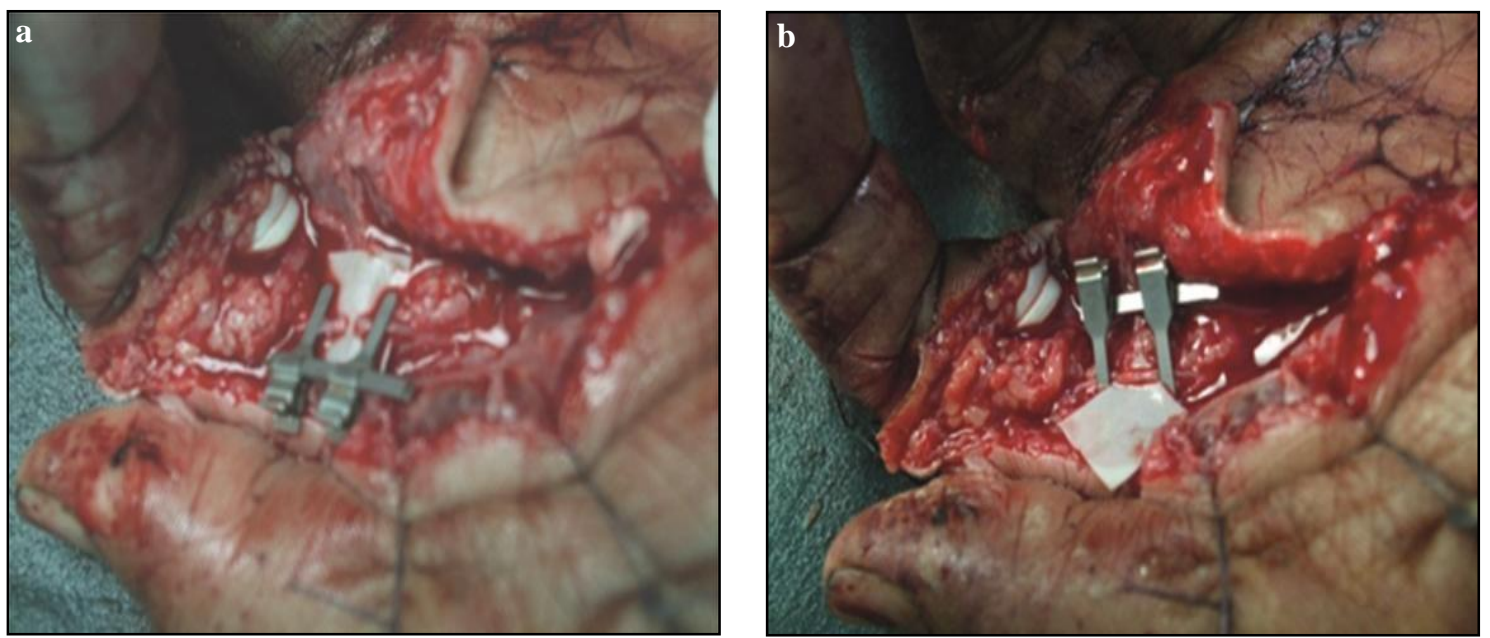

Figure (1) Shows $\underline{\mathbf{a}}$. intraoperative photo showing the digital artery of index finger between double vascular clamp prior to repair, $\underline{\mathbf{b}}$. after the repair

\section{Results}

The average follow up was 58 months. All fingers have been survived except six. The average time for bone union was 8 weeks. According to Chen's criteria, tab. (2) [5], the overall results were classified as grade I (excellent) in 20 cases,

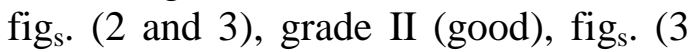
and 4 ) in 16 cases and grade III (fair) in 2 cases, tab. (3). The tendon function was excellent in 20 fingers, good in 26 fingers fair in 3 fingers, poor in 2 fingers and failure of 6 fingers. The 2 point discrimination was $6 \mathrm{~mm}$ in 9 fingers, $7-10 \mathrm{~mm}$ in 29 fingers, and $12-15 \mathrm{~mm}$ in 13 fingers. The mean grip and pinch strengths were
$80 \%$ and $85 \%$ respectively compared to contralateral hand. All of patient had returned to their normal daily activities. The tend on function was excellent in 20 fingers, good in 26 fingers fair in 3 fingers, poor in 2 fingers and failure of 6 fingers. The mean grip and pinch strengths were $80 \%$ and $85 \%$ respectively compared to contralateral hand. Tenolysis was performed in 6 digits, split thickness skin graft (Thiersch) in 3 digits with proximal level of amputation, and full thickness skin graft for 4 digits. All of patient had returned to their normal activities of life.

Table (2) Chen's criteria of functional evaluation after replantation

\begin{tabular}{|c|l|l|}
\hline \multirow{4}{*}{$\begin{array}{c}\text { Grade I } \\
\text { (Excellent) }\end{array}$} & A & $\begin{array}{l}\text { Ability to resume original work with a critical contribution from the } \\
\text { reattached parts }\end{array}$ \\
\cline { 2 - 3 } & B & $\begin{array}{l}\text { Collective range of joint motion exceeds } 60 \% \text { of normal, including the } \\
\text { joint immediately proximal to the reattached part }\end{array}$ \\
\cline { 2 - 3 } & C & $\begin{array}{l}\text { Recovery of sensibility to a high grade without excessive intolerance of } \\
\text { cold }\end{array}$ \\
\cline { 2 - 3 } & D & Muscular power of 4 to 5 on a scale of 1 to 5 \\
\hline
\end{tabular}




\begin{tabular}{|c|l|l|}
\hline \multirow{4}{*}{$\begin{array}{c}\text { Grade II } \\
\text { (Good) }\end{array}$} & A & Ability to resume some gainful work but not original employment \\
\cline { 2 - 3 } & C & Range of joint motion exceeds 40\% of normal \\
\cline { 2 - 3 } & D & $\begin{array}{l}\text { Recovery of near normal sensibility in the median and ulnar nerve } \\
\text { distributions without severe intolerance of cold }\end{array}$ \\
\hline \multirow{3}{*}{$\begin{array}{c}\text { Grade III } \\
\text { (Fair) }\end{array}$} & A & Independence in activities of daily living \\
\cline { 2 - 3 } & B & Range of motion of joints exceeds 30\% of normal \\
\cline { 2 - 3 } & D & Poor but useful recovery of sensibility \\
\hline $\begin{array}{c}\text { Grade IV } \\
\text { (Poor) }\end{array}$ & A & Muscular power of grade 3 \\
\hline
\end{tabular}
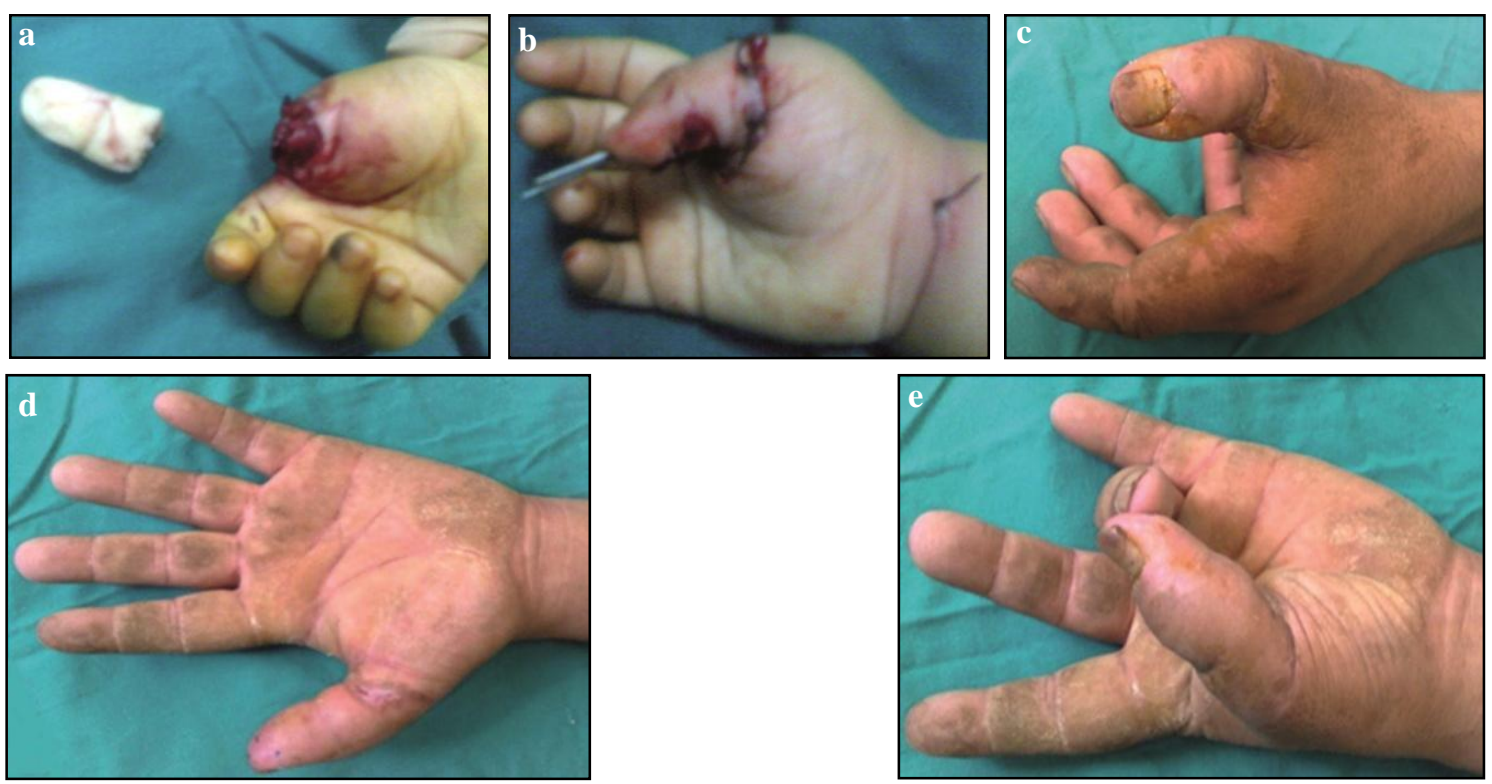

Figure (2) Shows a. "Patientno.1" preoperative photo showing complete amputation of the thump at PIPJ, b. immediately postoperative replantation, $\underline{\mathbf{c}}$. postoperative follow up photo with thumb flexion,

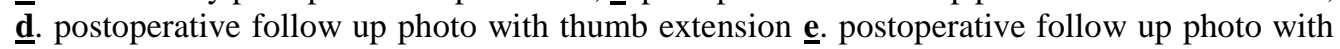
opposition
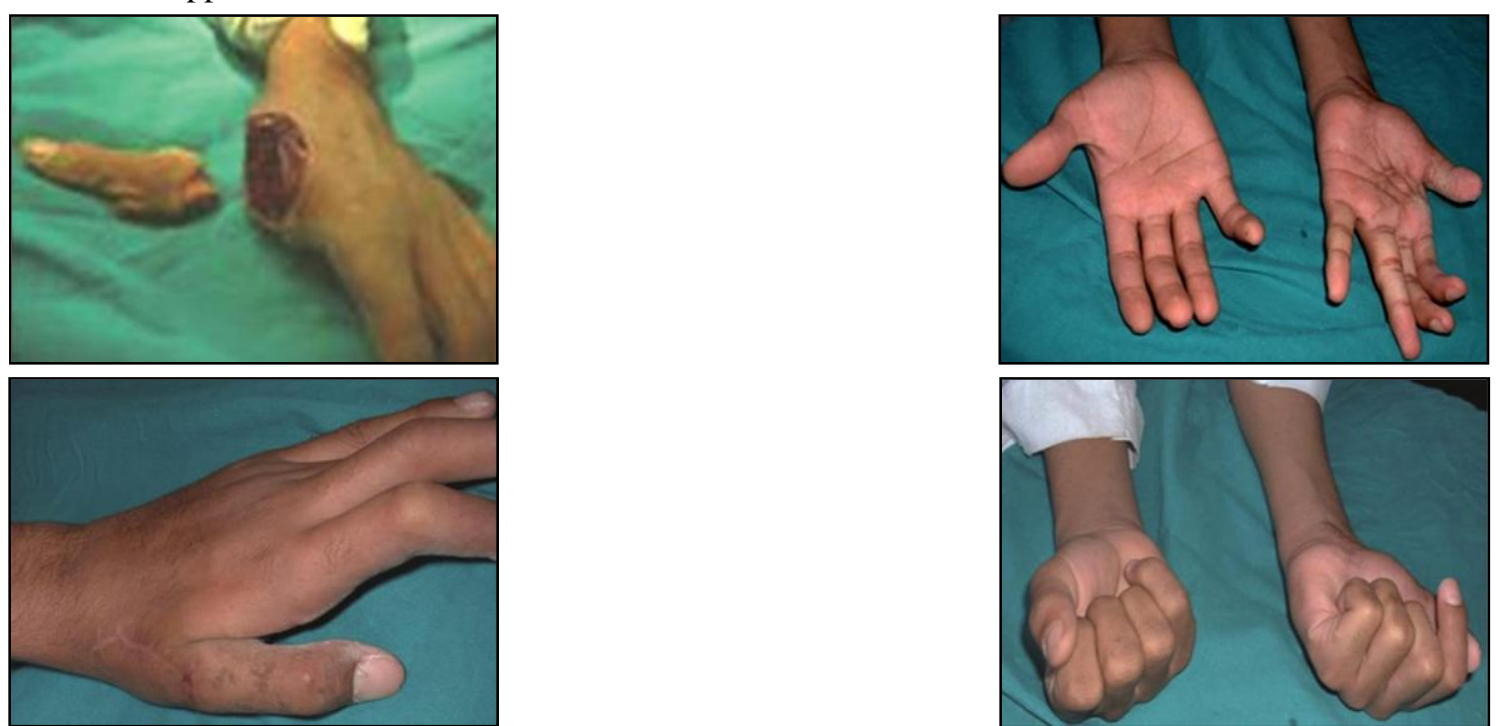

Figure (3) Shows a. "Patient no. 7" preoperative photo showing totally amputation of the left thumb at CMC joint $\underline{\mathbf{b}}$. follow up photo showing complete thumb extension $\underline{\mathbf{c}}$. scar on the dorsum of thumb $\underline{\mathbf{d}}$. flexion of the thumb and lack of flexion of index finger due to adhesion of flexor tendon 
Table (3) Functional outcome after finger replantation.

\begin{tabular}{|c|c|c|c|c|c|c|c|}
\hline Patient & $\begin{array}{l}\text { Failed } \\
\text { finger }\end{array}$ & Secondary procedure & $\begin{array}{l}\text { Follow } \\
\text { u (Ms) }\end{array}$ & $\begin{array}{l}\text { Chen's } \\
\text { grade }\end{array}$ & Grip $\%$ & Pinch $\%$ & $\begin{array}{c}\text { Two po ints } \\
\text { disc rimination } \\
\text { (mm) }\end{array}$ \\
\hline 1 & - & & 72 & I & 85 & 90 & 6 \\
\hline 2 & - & Full thickness skin graft & 86 & I & 90 & 95 & 7 \\
\hline 3 & - & Full thicknes skingraft & 90 & $\mathbf{I}$ & 86 & 90 & 8 \\
\hline 4 & . & & 48 & I & 75 & 80 & 8 \\
\hline 5. & - & & 92 & I & 90 & 95 & 6 \\
\hline 6 & - & & 88 & I & 87 & 90 & 6 \\
\hline 7 & - & & 69 & I & 85 & 80 & 7 \\
\hline 8 & - & $\begin{array}{l}\text { Tenolysis of index and } \\
\text { middle }\end{array}$ & 56 & II & 70 & 75 & 10 \\
\hline 9 & - & & 60 & $\mathbf{I}$ & 88 & 90 & 7 \\
\hline 10 & - & Tenolysis & 75 & II & 80 & 85 & 8 \\
\hline 11 & - & & 48 & $\mathbf{I}$ & 80 & 80 & 6 \\
\hline 12 & . & & 62 & I & 90 & 90 & 7 \\
\hline 13 & -. & & 68 & I & 85 & 90 & 6 \\
\hline 14 & - & & 42 & I & 90 & 90 & 7 \\
\hline 15 &.- & & 66 & I & 85 & 90 & 8 \\
\hline 16 &.- & & 90 & $\mathbf{I}$ & 90 & 90 & 6 \\
\hline 17 & $\begin{array}{l}\text { Index, } \\
\text { middle }\end{array}$ & & 48 & III & 50 & 55 & 12 \\
\hline 18 & \begin{tabular}{|l|l}
- & \\
\end{tabular} & & 36 & $\mathbf{I}$ & 90 & 90 & 6 \\
\hline 19 & -. & & 65 & II & 80 & 85 & 8 \\
\hline 20 & -. & Tenolysis & 56 & II & 70 & 75 & 9 \\
\hline 21 & . & Full thickness skingraft & 70 & II & 75 & 80 & 9 \\
\hline 22 & $\begin{array}{l}\text { Ring, } \\
\text { little }\end{array}$ & Thiersch graft & 74 & II & 60 & 60 & 12 \\
\hline 23 &.- & & 86 & $\mathbf{I}$ & 85 & 85 & 8 \\
\hline 24 & $-\cdot$ & Tenolysis & 68 & II & 75 & 80 & 10 \\
\hline 25 & Middle & & 54 & II & 70 & 70 & 12 \\
\hline 26 &.- & & 36 & I & 90 & 95 & 6 \\
\hline 27 & . & & 48 & II & 80 & 85 & 10 \\
\hline 28 & - & & 36 & I & 90 & 90 & 8 \\
\hline 29 & - & Thiersch graft & 68 & II & 70 & 70 & 12 \\
\hline 30 & 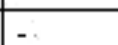 & & 64 & II & 75 & 75 & 10 \\
\hline 31 & - & Full thickness skin graft & 45 & II & 75 & 80 & 9 \\
\hline 32 & - & & 33 & I & 85 & 85 & 7 \\
\hline 33 & - & & 38 & II & 80 & 80 & 8 \\
\hline 34 & $\ldots$ & & 56 & I & 85 & 90 & 9 \\
\hline 35 & - & & 60 & II & 75 & 80 & 10 \\
\hline 36 & - & & 72 & III & 60 & 65 & 12 \\
\hline 37 & - & & 78 & II & 75 & 75 & 10 \\
\hline 38 &.- & Tenolysis & 60 & II & 75 & 80 & 11 \\
\hline
\end{tabular}
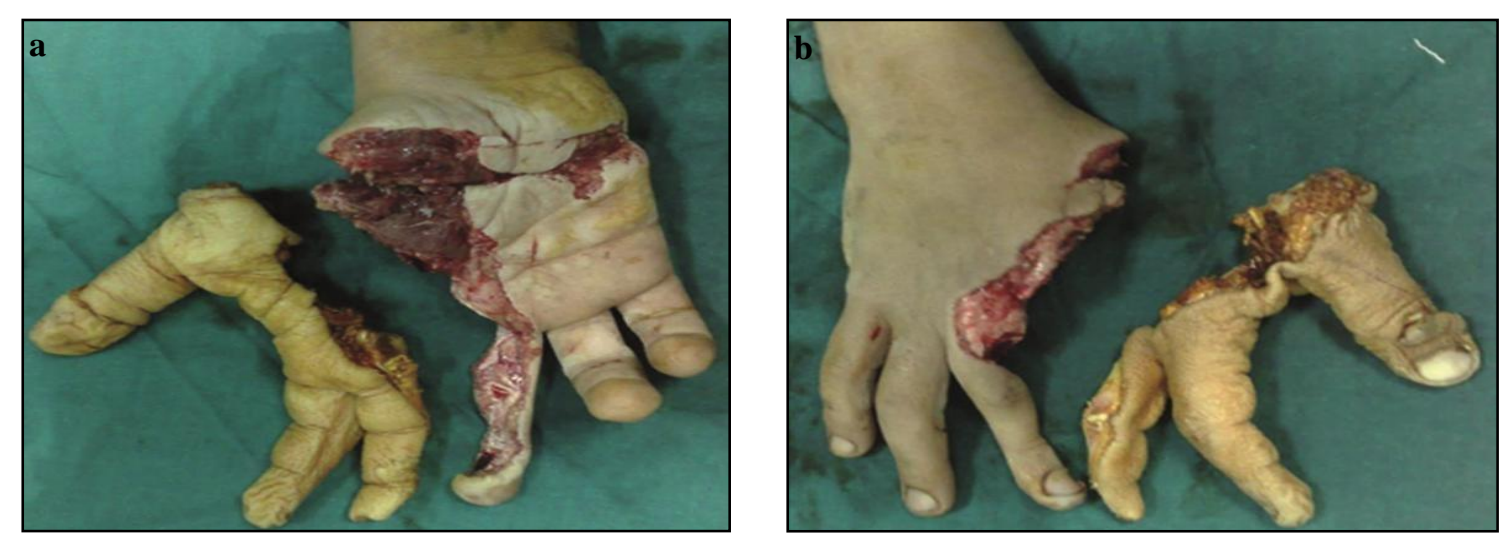

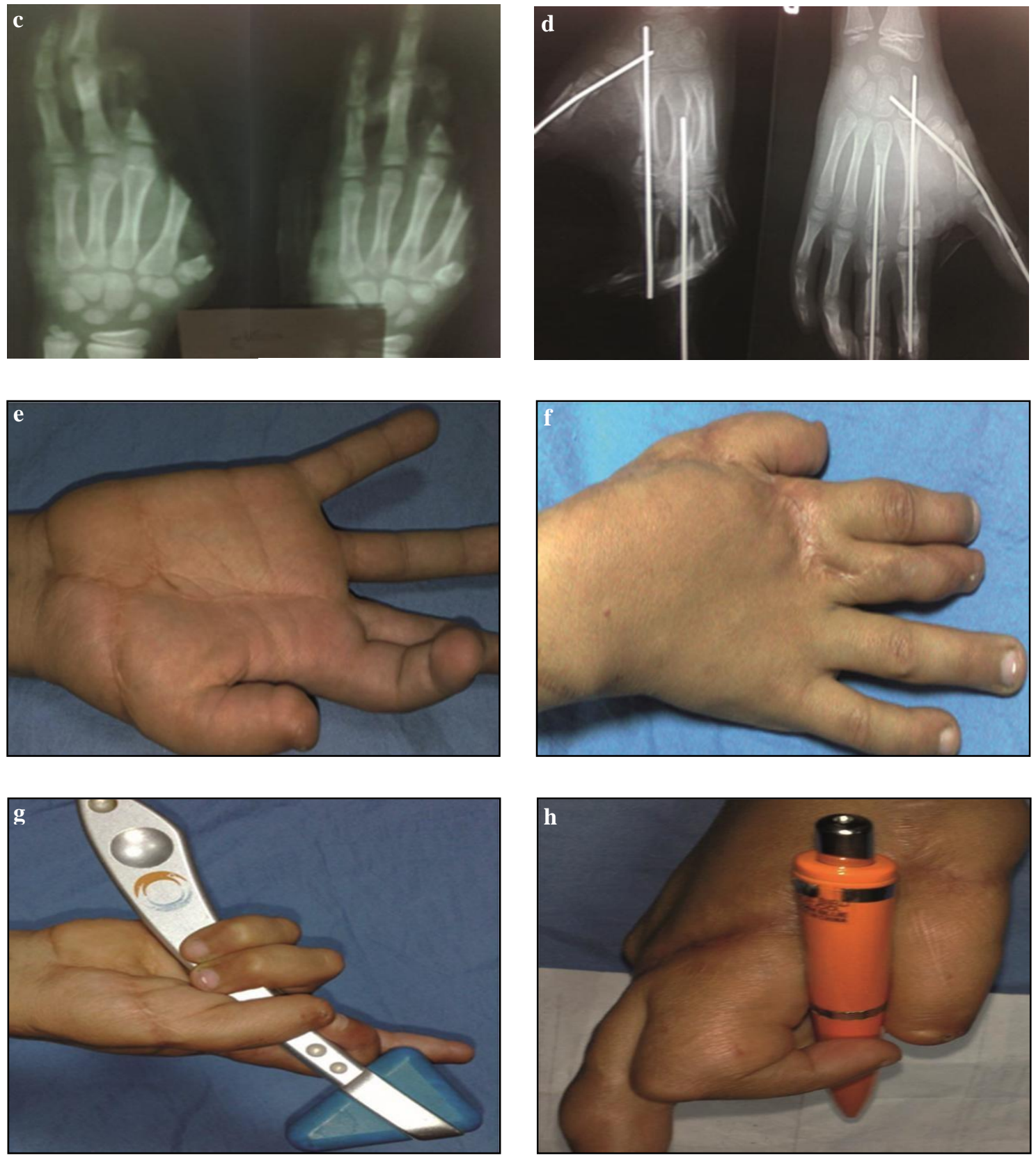

Figure (4) Shows a. Patient No. 8 preoperative photo showing amputation of thumb, index and middle finger $\underline{\mathbf{b}}$. preoperative photo showing dorsum of the hand and amputated fingers $\underline{\mathbf{c}}$. preoperative $\mathrm{x}$-ray showing the level of amputation of lateral three fingers $\underline{\mathbf{d}}$. postoperative $\mathrm{x}$ ray with k-wire fixation $\underline{\mathbf{e}}$. postoperative follow up photo showing survive of the laterat 3 fingers $\underline{\mathbf{f}}$. postoperative follow up photo showing complete extension of the lateral three fingers $\mathbf{g}$. Good grasp inspite of middle finger stiffness. $\underline{\mathbf{h}}$. postoperative follow up photo with writing position of the thumb and index fingers.

\section{Discussion}

Finger replantation is considered as a major task. On account of cultural beliefs amputation is not tolerated well in Eastern cultures. People with traumatic loss of fingers subjected to be blamed

from others [6]. The willing to hide the hand with amputated finger is the solution in such cases [6]. Even social deprivation is highly seen among these patients. The patient can pay a lot to save or replant the 
amputated finger [6]. Thus, a high rate of single finger replantation is seen. The goal of surgery is not only to save the finger but also to obtain reasonable functional outcome. Immediately after amputation the patient is looking forward to save the finger but later, is looking for meaningful finger function. Although there is advent in microsurgery, the functional outcome of finger replantation is still beyond the effort [6]. The survival rate of finger replantation is ranged between $80-90$ percent as described in the literature [1-3]. The different types of tissue, and different surgical procedure (bonefixation, vascularrepair, tendon repair and skin coverage) makes it difficult than single tissue transplant. The order for repairs was the osteosynthesis, digital artery, flexor tendon, dorsal vein, digital nerve, and extensor tendon can be repaired later, once blood flow has been reestablished to the injured finger. The lack of similarity in the cause of amputation and method for revascularization between different authors makes the study unbalanced and difficult to compare. There are different factors affecting the results of finger replantation. One of the most important factors is the age of the patient. Finger replantation is an absolute indication for replantation in children because of the development of the sensation and the need for high intellectual function. It well known that finger replantation in children is more difficult and gives functional result lowers than that of adult. This is due to the type of trauma because the child is usually subjected to crush injuries, for example machine (biscuit making machine, meet grinding machine, and corn grinding machine), door hinges, and kits (knife and kitchen machine). The second is the size of vessels specially that of the vein which is more delicate and smaller than that of the adult. The third is the lack of child cooperation and awareness which make it difficult for rehabilitation and followup [7,8]. In this study the number of involved children was 6 , their average age was 9 years. The number of involved fingers was 8 . The functional outcome according to Chen's criteria was excellent (grade I) in 3 cases ( 3 fingers), and good (grade II) in 3 cases (5fingers). Cause of injury is also has to be considered an important factor affecting functional outcome of finger replantation. In this study, the number of patients subjected to clean cut amputation (knife, glass, and electrical saw) was $13(30 \%)$ patients. The number of digital amputation was 19 (30\%) fingers. Their functional outcome according to Chen's criteria was excellent (grade I) in 11 patients (15 fingers), and good (grade II) in 2 patients (4 fingers). The number of patient subjected to crushed amputation (motor car accident, firearm injury, and machine injury) was25 (70\%) patients. The number of affected fingers was 38 (70 \%) fingers. Their functional outcome according to Chen's criteria was excellent (grade I) in 9 patients. Good (grade II) in 14 patients, and fair (grade III) in 2 patients, and loss of 5 fingers after replantation. Clean sharp amputation gives better result than that of crushed or avulsed amputation [9]. Although there are multiple procedures to save avulsed finger amputation but still the results are lower than that of clean cut amputation [10]. In crushed and avulsed amputation, the healthy zone is usually beyond the level of injury, specially the neurovascular structure. The proximal level of amputation gives better result than that of distal amputation. Both digital artery and vein have wide caliber proximally than distally. The incidence of secondary skin coverage is higher in the proximal replantation than that of distal amputation. Digital amputation at or distal to the distal interphalangeal joint was excluded in this study. Surgical experience is considered as an important factor to improve the functional outcome of finger replantation. It is not only important to try 
to replant but also very important to know which digit is candidate for replantation. The trial to do replantation for every case of amputation increases the failure rate and this will be burden on the functional outcome. The success rate for digital replantation is increasing by the development of learning curve and this also will come by experience. The surgical time for replantation is also decreased by experience. Surgical equipment is also play an important rule in the functional outcome of finger replantation. In certain cases especially in children, the use of surgical loupe is not sufficient enough to do vascular anastomosis. In some cases, the diameter of digital artery is smaller than the diameter of $10 / 0$ 's needle. Also the general condition of the patient and the associated medical disease is also considered as an important factor affecting the result of replantation [11]. In this study, we exclude cases with polytrauma and cases associated with medical diseases that increased the incidence of thrombosis. Surgeon comfortability plays an important factor to improve the functional outcome of finger replantation. Team work is one of the most important factors to avoid boring and improve the functional outcome for digital replantation specially in multiple digital amputation [11,12]. For this reason it is essential to do replantation by more than one team [11]. To improve the functional outcome of digital replantation, to relieve some stresses on the surgeon, the order of repair for multiple digital replantation should be considered. We advise to start with finger with best chance for successful replantation, best expected recovery and most significant contribution to function $[12,13]$. We prefer to repair the thumb, then the index, then the middle, then the ring and lastly the little finger, if all the fingers are injured equally and have the same chance for successful repair. While the order of repair done by Salah and Khalid [12] was the middle, then index, then ring and lastly the little finger. Patient cooperation is important, not only immediately after replantation but also during follow up. Because of the lack of cooperation between the children on one hand and both of the surgeon and the parents on the other hand, the functional outcome of digital replantation in children is lower than that of adult. Lindfors and Marttila [7] presented 29 patients with 38 finger injuries. Eight had a severe amputation injury. The success rate after total amputation was 6/14 (43\%), and after subtotal amputation was $13 / 15$. The success rates have been reported as $91.4 \%$ in guillotine amputations, $68.4 \%$ in crush injuries, and $66.3 \%$ in avulsion type injuries [4,9]. Matsuzaki et al. [13] reported that the success rate for complete replantation was $93 \%$ (27/29) and $95 \%$ (39/41) for near-amputation. This study was included 70 digits came from 43 patients (average age, 46 years; range, 19 to 78 years; 37 men). In all 39 digits from 21 patients required 48 secondary surgeries; skin grafts, tenolysis, joint fusion, bone graft, osteotomy, and web-plasty. The incidence for secondary soft tissue coverage increased with proximal amputation. In this study, the success rate for complete replantation was $90.5 \%$ (52/57). Tenolysis was performed in 6 digits, split thickness skin graft in 4 digits with proximal level of amputation while full thickness skin graft in 4 digits. To improve the functional outcome of finger replantation, the surgeons have to be comfortable, alert in assessment and repair, work under ease in good team and with suitable surgical equipment. 


\section{Conclusion}

Fingers amputation commonly occur secondary to different modes of trauma which affect the prognosis after reconstruction of the amputated digit. The prognosis is better in clean cut injury rather than avulsion injury.

\section{References}

[1] Boulas, H. (1998). Amputations of the fingers and hand: indications for Replantation, J. Am Acad Orthop Sur., Vol. 6: 100-105.

[2] Medling, B., Bueno, R., Russell, R., et al. (2007). Replantation outcomes. Clin Plast Surg. 34: 177-185.

[3] Pederson, W. (2001). Replantation. Plast Reconstr Surg. 107: 823-841.

[4] Dec, W. (2006). A meta-analysis of success rates for digit replantation. Tech Hand up extreme surg. 10: 124-129.

[5] Chen, Z., Meyer, V., Kleinert, H., et al. (1981). Present indications and contraindications for replantation as reflected by long-term functional results. Orthop Clin North Am. 12: 49-870.

[6] Soucacos, P., (2001). Indications and selection for digital amputation and Replantation. J. Hand Surg Br. 26: 572-581.

[7] Lindfors, N., Marttila, I. (2012). Replantation or revascularization injuries in children: Incidence, epidemiology, and outcome. J. Plast Surg Hand Surg. 46 (5): 359-363.

[8] Noaman, H. (2008). Microsurgery in children: History, indications, precautions, and differences from that of adults. Microsurgery. 28 (2): 83-84.
[9] Sebastin, S., Chung, K. (2011). A systematic review of the outcomes of replantation of distal digital replantation. Plast Reconstr Surg. 128 (3): 723-737.

[10] Noaman, H. (2012). Salvage of complete degloved digits with reversed vascularized pedicled forearm flap: A new technique. J. Hand Surg Am. 37 (4): 832-836.

[11] Nanda, V., Jacob, J., Alsafy, T., et al. (2011). Replantation of an amputated hand: A rare case report and acknowledgement of a multidis-ciplinary team input. Oman Medical Journal. 26 (4): 279-282

[12] Salah, M., Khaled, N. (2008). Replantation of multiple digits and hand amputations: four case report. Cases Journal. 1: 266-272

[13] Umit, K., Selim, C., Halil, B. (2010). Successful Replantation in ten digit amputation. Acta Orthop Traumatol Turc. 44 (1): 76-78.

[14] Matsuzaki H, Kouda H, Maniwa K. (2012). Secondary surgeries after digital replantations a case series. Hand Surg. 17(3): 351-357. 